\title{
Nanocrystal Core Size and Shape Substitutional Doping and Underlying Crystalline Order in Nanocrystal Superlattices
}

Davit Jishkariani,,$^{\dagger, \|, \#}$ Katherine C. Elbert, ${ }^{\dagger, \#}$ Yaoting $W u,{ }^{\dagger, \#}$ Jennifer D. Lee, ${ }^{\dagger}$ Michiel Hermes, ${ }^{\ddagger}$ Da Wang, ${ }^{\ddagger}, \perp$ Alfons van Blaaderen, ${ }^{\star}$ and Christopher B. Murray ${ }^{*}, \uparrow$

${ }^{\dagger}$ Department of Chemistry, University of Pennsylvania, Philadelphia, PA 19104, United States †Soft Condensed Matter, Debye Institute for Nanomaterials Science, Utrecht University, Princetonplein 5, 3584 CC Utrecht, The Netherlands

${ }^{\S}$ Department of Materials Science and Engineering, University of Pennsylvania, Philadelphia, PA 19104, United States

\section{Present Addresses}

"Chemical and Nanoparticle Synthesis Core (CNSC), University of Pennsylvania, Philadelphia, PA 19104, United States.

${ }^{\perp}$ Electron Microscopy for Materials Science (EMAT), University of Antwerp, Groenenborgerlaan 171, 2020 Antwerp, Belgium.

KEYWORDS: Mesoscale doping, substitutional doping, self-assembly, nanoparticle dendron hybrids, dendritic ligands. 


\section{Additional microscopy images}
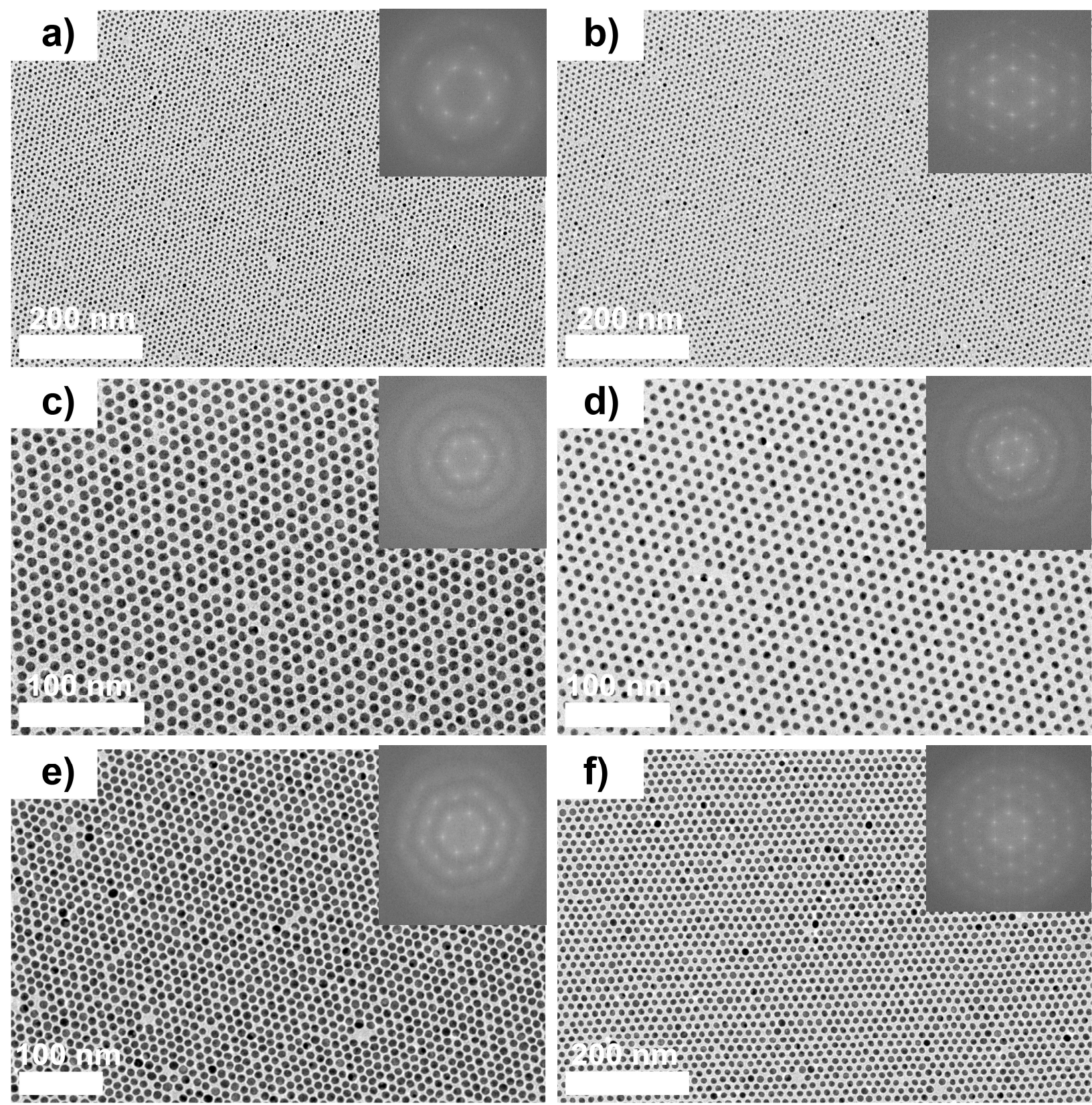

Figure S1. TEM micrographs of self-assembled a) small dendrimer $\mathbf{1}$ and b) large dendrimer $\mathbf{2}$ coated $5.2 \pm 0.5 \mathrm{~nm}$ Au NCs, c) small dendrimer 1 and d) large dendrimer 2 coated 7.6 $\pm 0.5 \mathrm{~nm} \mathrm{Au}$ NCs, and e) small dendrimer 1 and f) large dendrimer 2 coated 10.2 $\pm 0.6 \mathrm{~nm} \mathrm{Au} \mathrm{NCs.}$ 

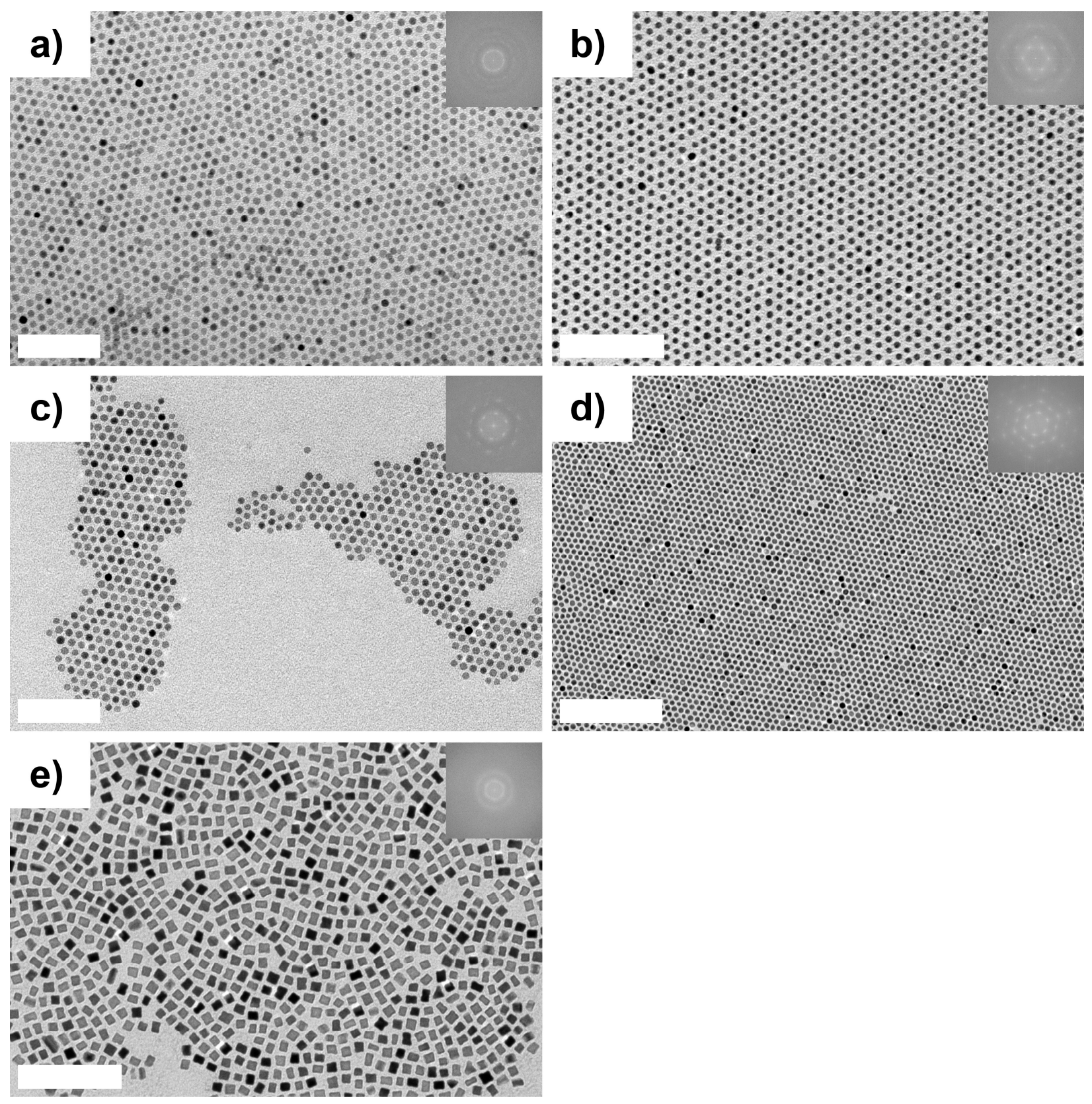

Figure S2. TEM micrographs of self-assembled a) ligand 4 coated $9.5 \pm 0.8 \mathrm{~nm}$ MZF, b) large dendron 2 coated $6.6 \pm 0.4 \mathrm{~nm} \mathrm{Au}, \mathrm{c}$ ) ligand 4 coated $8.9 \pm 0.8 \mathrm{~nm} \mathrm{MZF}$, small dendron 3 coated 10.2 \pm 0.6 $\mathrm{Au}$, and small dendron 3 coated $9.5 \pm 0.8$ (cube side) $\mathrm{nm}$ Pt NCs. Scale bars in (a-c, e) are $100 \mathrm{~nm}$ and in (d) $200 \mathrm{~nm}$. 
Table S1. Core size, effective ligand length, overall size, and "softness" of small and large ligand coated different size NCs.

\begin{tabular}{|c|c|c|c|c|c|c|}
\hline Entry & Abbreviation & $\begin{array}{l}\text { Inorganic } \\
\text { core } \\
\text { diameter } \\
(\mathrm{nm})^{\mathrm{a}}\end{array}$ & $\begin{array}{l}\text { Inorganic } \\
\text { core radius } \\
\quad(\mathrm{nm})^{\mathrm{b}}\end{array}$ & $\begin{array}{l}\text { Ligand effective } \\
\text { length (nm) } \\
\text { (interparticle } \\
\text { separation / 2) }\end{array}$ & $\begin{array}{c}\text { Whole particle } \\
\text { effective size ((NC } \\
\text { core size + Ligand } \\
\text { Effective length) x 2) }\end{array}$ & $\begin{array}{c}\text { NC "Softness" \% } \\
\text { (Ligand effective } \\
\text { length/ Ligand } \\
\text { effective length }+ \\
\text { NC core radius x } \\
100 \%)^{\mathrm{b}}\end{array}$ \\
\hline 1 & $5.2 \pm 0.5 \mathrm{~nm} \mathrm{Au} @ 1$ & $5.2 \pm 0.5$ & 2.6 & 2.15 & 9.5 & 45.3 \\
\hline 2 & $5.2 \pm 0.5 \mathrm{~nm} \mathrm{Au} @ 2$ & $5.2 \pm 0.5$ & 2.6 & 2.7 & 10.6 & 50.9 \\
\hline 3 & $7.6 \pm 0.5 \mathrm{~nm} \mathrm{Au} @ 1$ & $7.6 \pm 0.5$ & 3.8 & 1.75 & 11.1 & 31.5 \\
\hline 4 & $7.6 \pm 0.5 \mathrm{~nm} \mathrm{Au} @ 2$ & $7.6 \pm 0.5$ & 3.8 & 2.8 & 13.2 & 42.4 \\
\hline 5 & 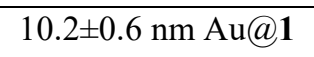 & $10.2 \pm 0.6$ & 5.1 & 1.25 & 12.7 & 19.7 \\
\hline 6 & $10.2 \pm 0.6 \mathrm{~nm} \mathrm{Au} @ 2$ & $10.2 \pm 0.6$ & 5.1 & 2.6 & 15.4 & 33.8 \\
\hline 7 & $10.2 \pm 0.6 \mathrm{~nm} \mathrm{Au} @ 3$ & $10.2 \pm 0.6$ & 5.1 & 1.4 & 13.0 & 21.5 \\
\hline 8 & $6.1 \pm 0.5$ nm Au@1 & $6.1 \pm 0.5$ & 3.1 & 2.0 & 10.1 & 39.2 \\
\hline 9 & 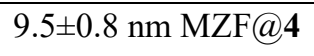 & $9.5 \pm 0.8$ & 4.8 & 1.7 & 12.9 & 26.2 \\
\hline 10 & $6.6 \pm 0.4 \mathrm{~nm} \mathrm{Au} @ 2$ & $6.6 \pm 0.4$ & 3.3 & 2.6 & 11.8 & 44.1 \\
\hline 11 & $8.9 \pm 0.8$ nm MZF@4 & $8.9 \pm 0.8$ & 4.5 & 1.2 & 11.3 & $21 / 1$ \\
\hline 12 & $9.5 \pm 0.8 \mathrm{~nm} \mathrm{Pt} @ 3$ & $9.5 \pm 0.8^{\mathrm{a}}$ & $4.8^{\mathrm{b}}$ & 1.7 & 12.9 & - \\
\hline
\end{tabular}

${ }^{\mathrm{a}}$ For cube, the side value is used. ${ }^{\mathrm{b}}$ For cube, the $1 / 2$ of the cube side value is used. 
Table S2. Self-assembly motifs observed in mixtures of small and large ligand coated different size NCs.

\begin{tabular}{|c|c|c|c|c|c|c|}
\hline \multirow[b]{2}{*}{ Entry } & \multicolumn{2}{|c|}{ NC 1} & \multicolumn{2}{|c|}{ NC 2} & \multicolumn{2}{|c|}{ Mixing } \\
\hline & Name & $\begin{array}{c}\text { Whole particle } \\
\text { effective size } D_{1} \\
(\mathrm{~nm})\end{array}$ & Name & $\begin{array}{c}\text { Whole particle } \\
\text { effective size } \\
D_{2}(\mathrm{~nm}) \\
\end{array}$ & $\begin{array}{c}\text { Observed major } \\
\text { self-assembly } \\
\text { motifs }\end{array}$ & $\begin{array}{l}\text { Whole particle } \\
\text { diameter ratio } \\
\left(\mathrm{D}_{1} / \mathbf{D}_{2} \text { or } \mathbf{D}_{2} / \mathbf{D}_{1}\right)^{\mathrm{a}}\end{array}$ \\
\hline 1 & $\begin{array}{c}5.2 \pm 0.5 \mathrm{~nm} \\
\mathrm{Au} @ \mathbf{1} \\
\end{array}$ & 9.5 & $\begin{array}{c}7.6 \pm 0.5 \mathrm{~nm} \\
\mathrm{Au} @ 1 \\
\end{array}$ & 11.1 & Self-separation & 0.86 \\
\hline 2 & $\begin{array}{c}5.2 \pm 0.5 \mathrm{~nm} \\
\mathrm{Au} @ 2 \\
\end{array}$ & 10.6 & $\begin{array}{c}7.6 \pm 0.5 \mathrm{~nm} \\
\mathrm{Au} @ 1 \\
\end{array}$ & 11.1 & Doping & 0.96 \\
\hline 3 & $\begin{array}{c}5.2 \pm 0.5 \mathrm{~nm} \\
\mathrm{Au} @ \mathbf{1}\end{array}$ & 9.5 & $\begin{array}{c}7.6 \pm 0.5 \mathrm{~nm} \\
\mathrm{Au} @ 2 \\
\end{array}$ & 13.2 & $\begin{array}{l}\text { Self-separation, } \\
\text { Disordered phase }\end{array}$ & 0.72 \\
\hline 4 & $\begin{array}{c}5.2 \pm 0.5 \mathrm{~nm} \\
\mathrm{Au} @ 2\end{array}$ & 10.6 & $\begin{array}{c}7.6 \pm 0.5 \mathrm{~nm} \\
\mathrm{Au} @ 2 \\
\end{array}$ & 13.2 & $\begin{array}{c}\text { Doping, Self- } \\
\text { separation }\end{array}$ & 0.80 \\
\hline 5 & $\begin{array}{c}5.2 \pm 0.5 \mathrm{~nm} \\
\mathrm{Au} @ 1\end{array}$ & 9.5 & $\begin{array}{l}10.2 \pm 0.6 \mathrm{~nm} \\
\mathrm{Au} @ 1\end{array}$ & 12.7 & Self-separation & 0.75 \\
\hline 6 & $\begin{array}{c}5.2 \pm 0.5 \mathrm{~nm} \\
\mathrm{Au} @ 2\end{array}$ & 10.6 & $\begin{array}{c}10.2 \pm 0.6 \mathrm{~nm} \\
\mathrm{Au} @ 1\end{array}$ & 12.7 & Self-separation & 0.84 \\
\hline 7 & $\begin{array}{c}5.2 \pm 0.5 \mathrm{~nm} \\
\mathrm{Au} @ \mathbf{1}\end{array}$ & 9.5 & $\begin{array}{c}10.2 \pm 0.6 \mathrm{~nm} \\
\mathrm{Au} @ 2 \\
\end{array}$ & 15.4 & $\begin{array}{l}\text { Self-separation, } \\
\text { Disordered phase }\end{array}$ & 0.62 \\
\hline 8 & $\begin{array}{c}5.2 \pm 0.5 \mathrm{~nm} \\
\mathrm{Au} @ 2\end{array}$ & 10.6 & $\begin{array}{c}10.2 \pm 0.6 \mathrm{~nm} \\
\mathrm{Au} @ 2\end{array}$ & 15.4 & $\begin{array}{l}\text { Self-separation, } \\
\text { Binary (AB5) }\end{array}$ & 0.69 \\
\hline 9 & $\begin{array}{c}7.6 \pm 0.5 \mathrm{~nm} \\
\mathrm{Au} @ \mathbf{1} \\
\end{array}$ & 11.1 & $\begin{array}{c}10.2 \pm 0.6 \mathrm{~nm} \\
\mathrm{Au} @ 1 \\
\end{array}$ & 12.7 & Self-separation & 0.87 \\
\hline 10 & $\begin{array}{c}7.6 \pm 0.5 \mathrm{~nm} \\
\mathrm{Au} @ 2\end{array}$ & 13.2 & $\begin{array}{c}10.2 \pm 0.6 \mathrm{~nm} \\
\mathrm{Au} @ 1\end{array}$ & 12.7 & $\begin{array}{c}\text { Doping, Self- } \\
\text { separation, } \\
\text { Disordered phase }\end{array}$ & 0.96 \\
\hline 11 & $\begin{array}{c}7.6 \pm 0.5 \mathrm{~nm} \\
\mathrm{Au} @ \mathbf{1}\end{array}$ & 11.1 & $\begin{array}{c}10.2 \pm 0.6 \\
\mathrm{Au} @ 2\end{array}$ & 15.4 & Self-separation & 0.72 \\
\hline 12 & $\begin{array}{c}7.6 \pm 0.5 \mathrm{~nm} \\
\mathrm{Au} @ 2\end{array}$ & 13.2 & $\begin{array}{c}10.2 \pm 0.6 \mathrm{~nm} \\
\mathrm{Au} @ 2\end{array}$ & 15.4 & Disordered phase & 0.86 \\
\hline 13 & $\begin{array}{c}7.6 \pm 0.5 \mathrm{~nm} \\
\mathrm{Au} @ \mathbf{2}\end{array}$ & 13.2 & $\begin{array}{c}9.5 \pm 0.8 \mathrm{~nm} \\
\mathrm{MZF} @ 4 \\
\end{array}$ & 12.9 & $\begin{array}{c}\text { Doping, Self- } \\
\text { separation } \\
\end{array}$ & 0.98 \\
\hline 14 & $\begin{array}{c}10.2 \pm 0.6 \mathrm{~nm} \\
\mathrm{Au} @ 2\end{array}$ & 15.4 & $\begin{array}{c}9.5 \pm 0.8 \mathrm{~nm} \\
\mathrm{MZF} @ 4 \\
\end{array}$ & 12.9 & $\begin{array}{c}\text { Doping, Self- } \\
\text { separation } \\
\end{array}$ & 0.84 \\
\hline 15 & $\begin{array}{c}6.6 \pm 0.4 \mathrm{~nm} \\
\mathrm{Au} @ 2 \\
\end{array}$ & 8.78 & $\begin{array}{c}8.9 \pm 0.8 \mathrm{~nm} \\
\mathrm{MZF} @ 4 \\
\end{array}$ & 11.3 & $\begin{array}{c}\text { Doping, Self- } \\
\text { separation } \\
\end{array}$ & 0.78 \\
\hline 16 & $\begin{array}{c}7.6 \pm 0.5 \mathrm{~nm} \\
\mathrm{Au} @ 2\end{array}$ & 13.2 & $\begin{array}{c}9.5 \pm 0.8 \mathrm{~nm} \\
\mathrm{Pt} @ 3 \\
\end{array}$ & 12.9 & Self-separation & 0.98 \\
\hline 17 & $\begin{array}{c}10.2 \pm 0.6 \mathrm{~nm} \\
\mathrm{Au} @ 3\end{array}$ & 11.55 & $\begin{array}{c}9.5 \pm 0.8 \mathrm{~nm} \\
\mathrm{Pt} @ 3 \\
\end{array}$ & 12.9 & $\begin{array}{c}\text { Doping, Self- } \\
\text { separation } \\
\end{array}$ & 0.90 \\
\hline 18 & $\begin{array}{c}10.2 \pm 0.6 \mathrm{~nm} \\
\mathrm{Au} @ 2 \\
\end{array}$ & 15.4 & $\begin{array}{c}9.5 \pm 0.8 \mathrm{~nm} \\
\mathrm{Pt} @ 3 \\
\end{array}$ & 12.9 & $\begin{array}{l}\text { Doping, Binary } \\
\text { (AB) }\end{array}$ & 0.84 \\
\hline
\end{tabular}

${ }^{\mathrm{a}}$ For simplicity, the smaller value is divided by a larger value. 


\section{Particle tracking analysis.}

Particle tracking analysis was performed on images provided in Figures $3 \mathrm{c}$ and 6a. The representative example (Figure 6a) with detailed analysis is provided below.
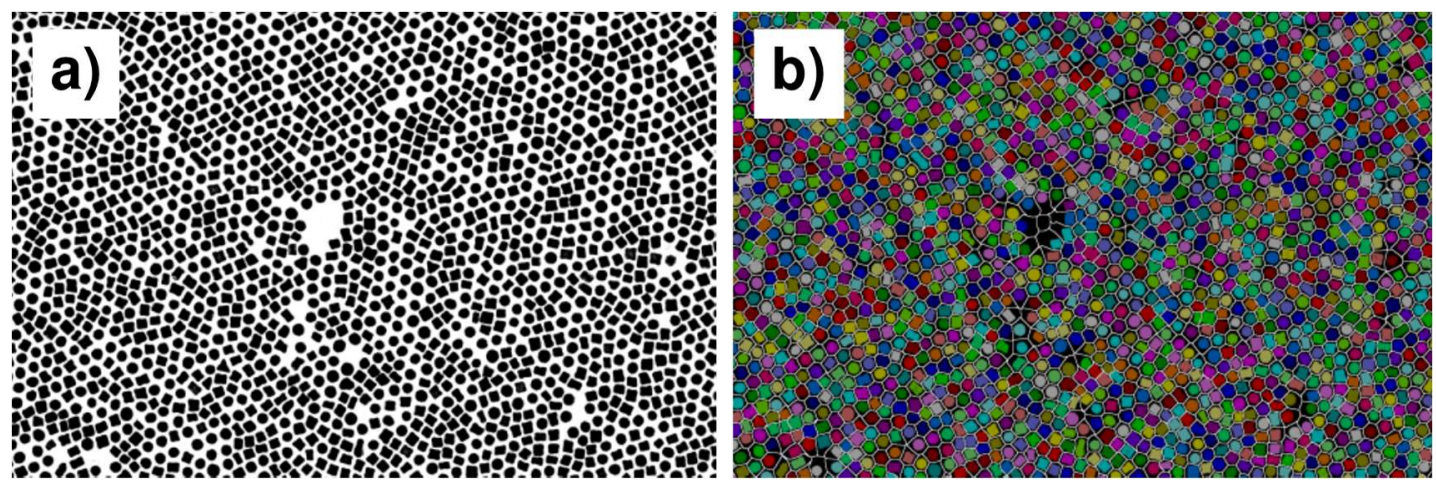

c)
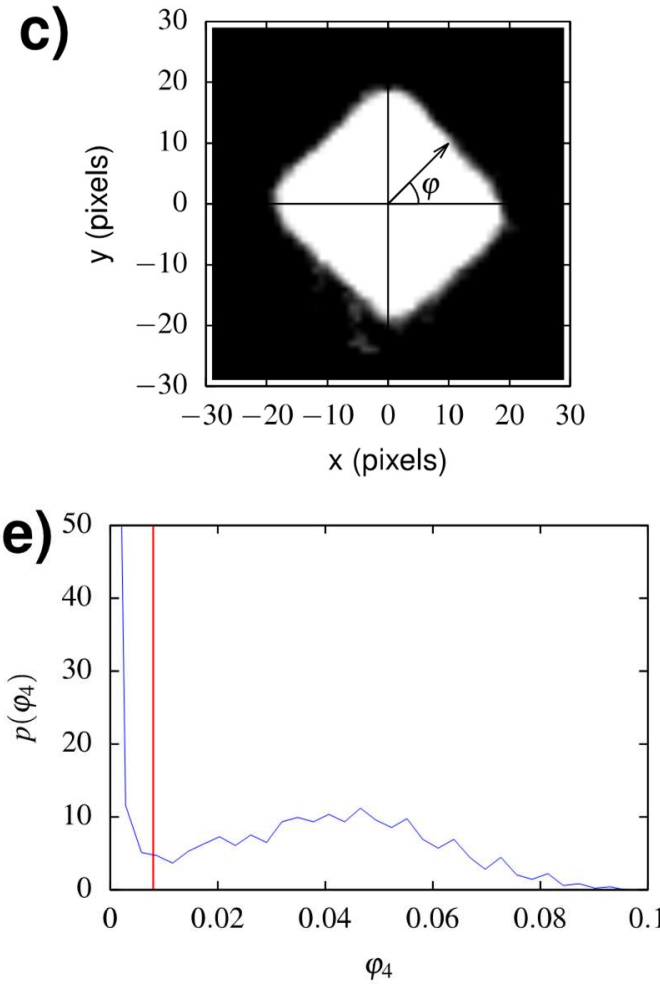

d)
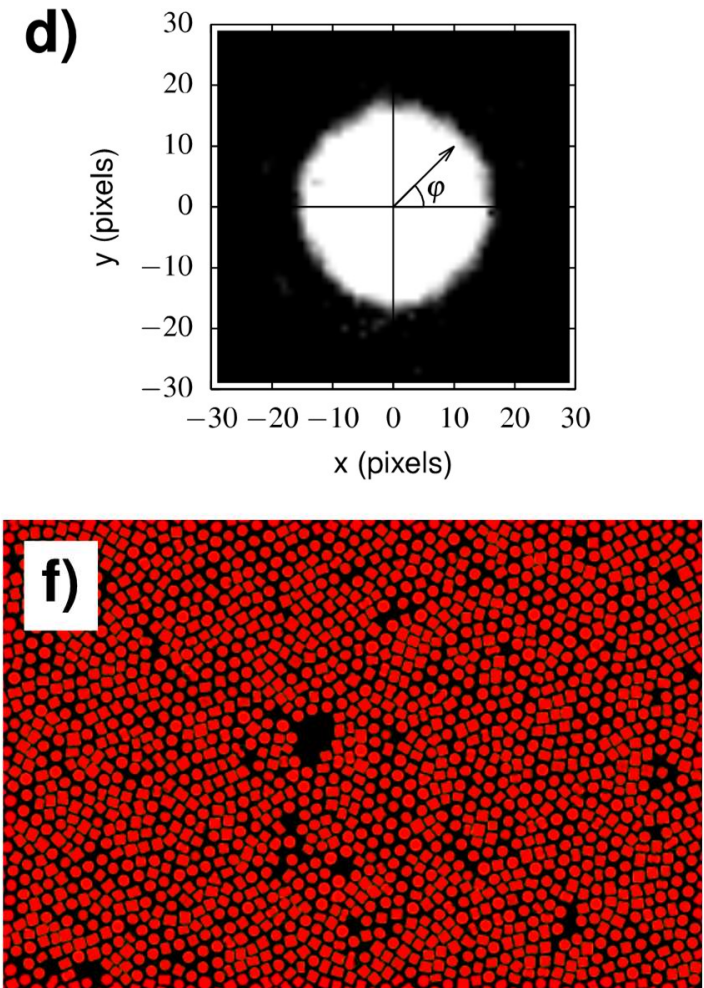

Figure S3: (a) a 2D layer formed by a binary mixture of spheres and cubes. (b) a watershed algorithm is used to segment the image into individual particles. (c) a cubic particle taken from the negative of (a). The $\varphi$ denotes the polar angle that is used to calculate $\varphi_{4}$. (d) same as $\mathrm{c}$ but for a spherical particle. (e) The distribution of $\varphi_{4}$ from the image shown in $a, b$ and $f$. The vertical line denotes the threshold value that was used. (f) An overlay of the located spheres and cubes.

To determine the location and type of the individual particles we first segment the image into regions belonging to single particle by using a watershed algorithm. The result of this segmentation is shown in Figure S3b. We can then determine the location of the 
particle from the center of the intensity of these regions. We then switch to polar coordinates $\varphi$ and $r$ and place the particle in the center of this coordinate system to determine if a particle is a sphere or a cube. We calculate the complex number

$$
\phi_{4}=\frac{1}{C} \sum_{\text {pixels }} I^{2}(r, \varphi) r^{2} \exp (i 4 \varphi)
$$

where the sum is over all pixels in the region and $I(r, \varphi)$ is the intensity of the pixel located $r$ away from the center at polar angle $C=\sum_{\text {pixels }} I^{2}(r, \varphi) r^{2}$. We have weighted the brighter pixels and the pixels further away from the center of mass more heavily to get a clearer separation between the two particle shapes.

We take the norm of this complex number $\varphi_{4}=\left|\varphi_{4}\right|$ and plot its distribution in Figure S3e. Spherical particles, that show up as circles, have a very symmetrical distribution of intensity around the center of mass and a low $\varphi_{4}$ while cubes, showing up as squares, have a high $\varphi_{4}$. For this sample we have chosen a value of 0.008 to separate cubes from spheres.

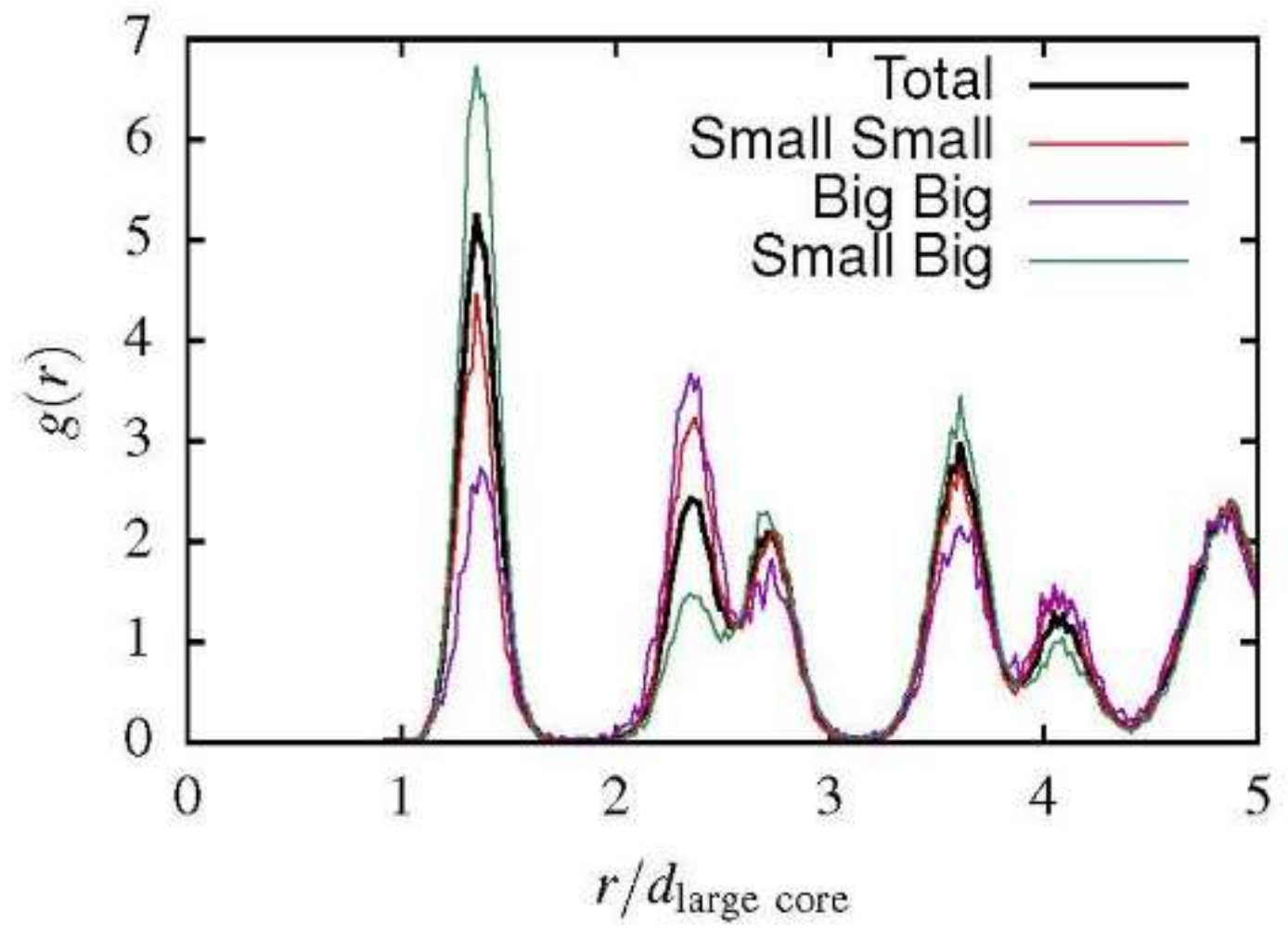

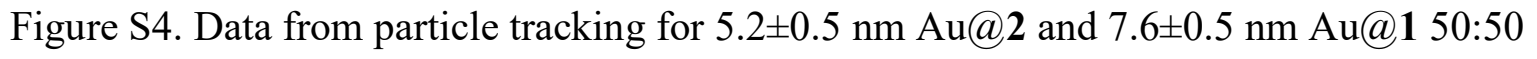
mixture. 

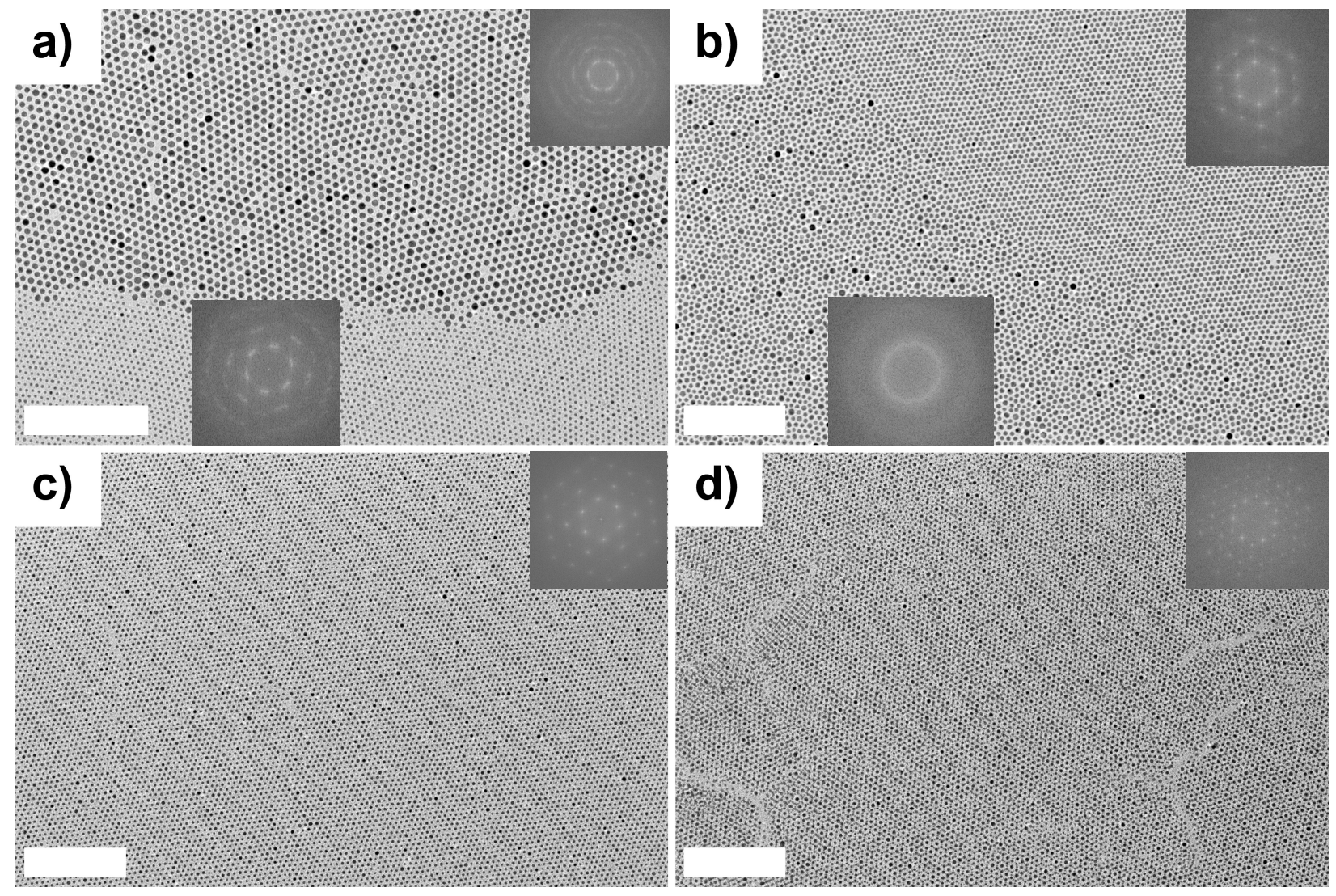

Figure S5. TEM micrographs of binary mixtures of a) 10.2 $\pm 0.6 \mathrm{~nm} \mathrm{Au@1} \mathrm{and} 5.2 \pm 0.5 \mathrm{~nm}$

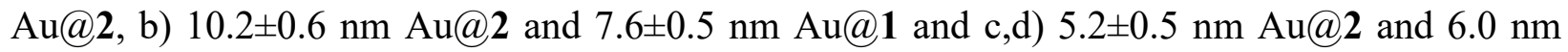
$\mathrm{Au} @ 1$. Scale bars are $200 \mathrm{~nm}$. FFTs of each self-assembly pattern are also provided within corresponding patterns 


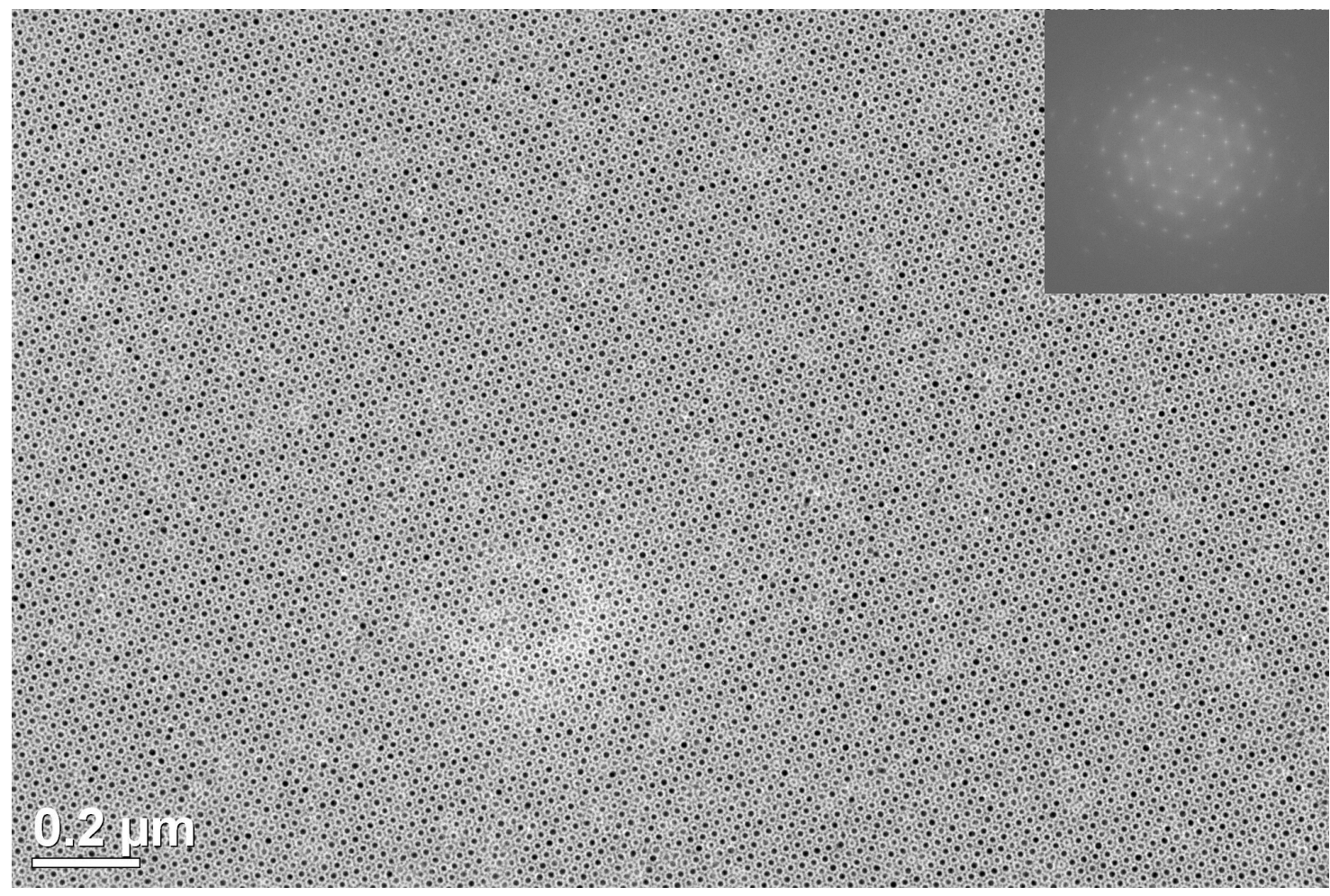

Figure S6. Large area TEM micrograph of $\mathrm{AB}_{5}$ type binary superlattice obtained by mixing $\mathrm{G} 2$

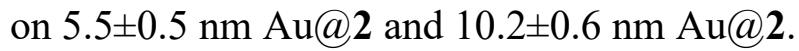




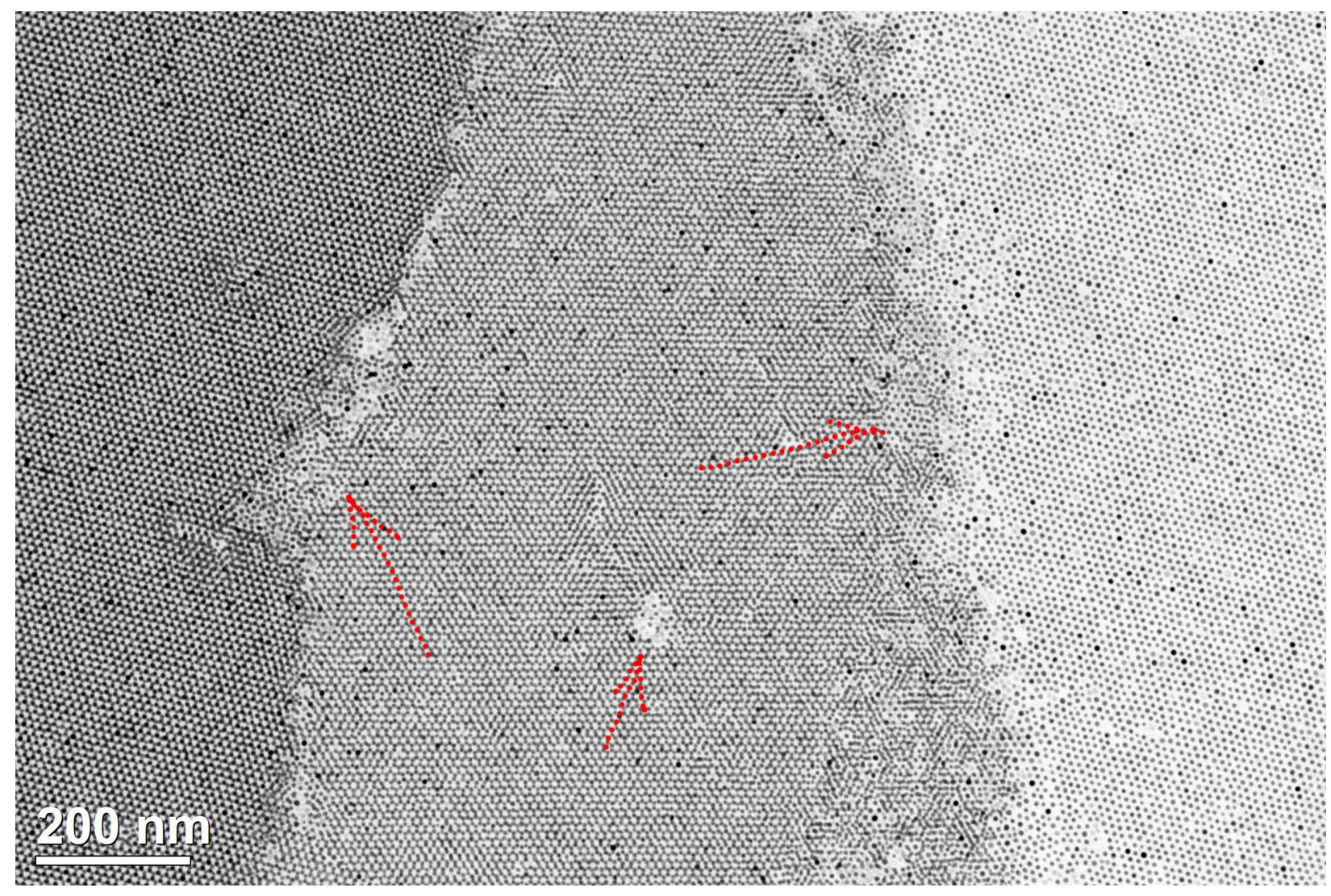

Figure S7. Large area TEM micrograph of superlattices obtained from the mixture of $6.6 \pm 0.4 \mathrm{~nm}$

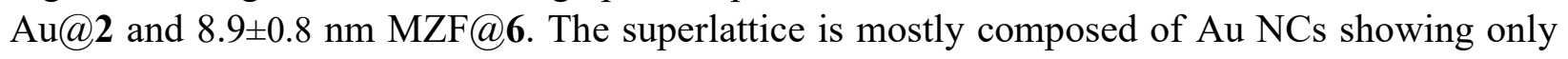
negligible doping while most MZF NCs are expelled out of the superlattice and reside within imperfections (shown by red arrows). 

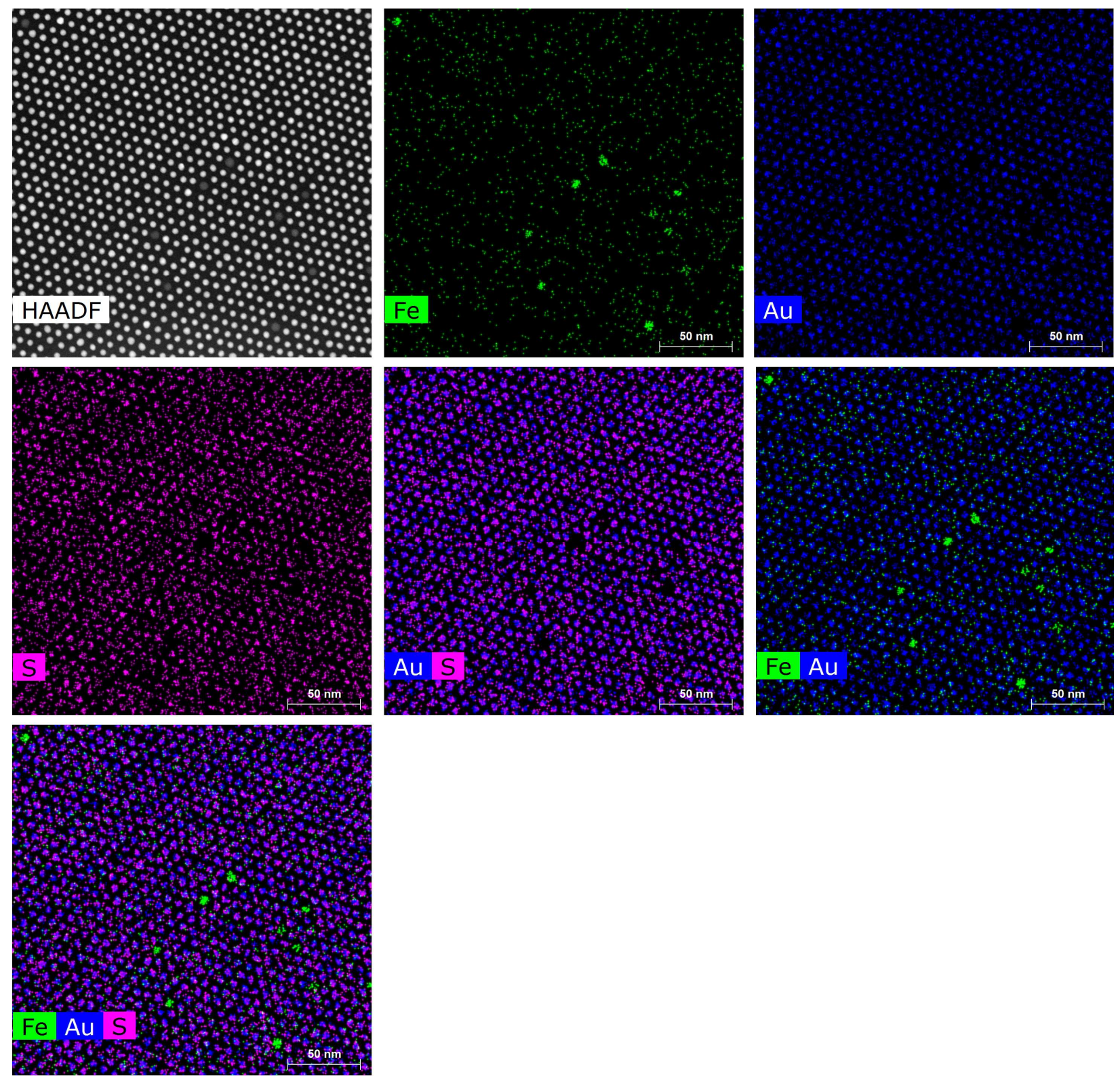

Figure S8. Energy Dispersive X-ray Spectroscopy (EDX) mapping of ligand 4 coated $8.9 \pm 0.8$

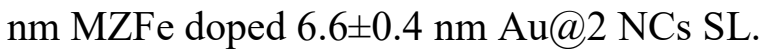




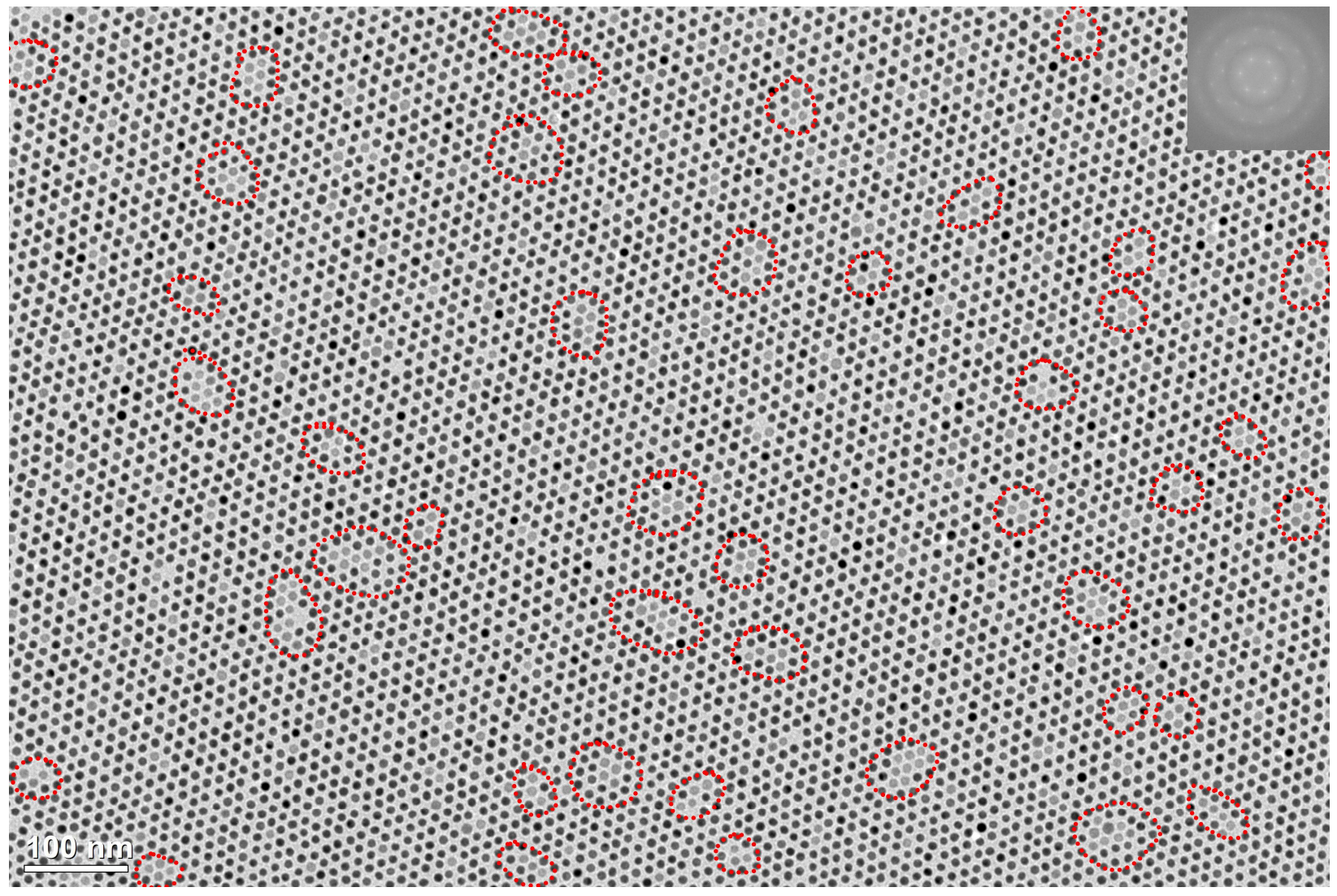

Figure S9. Large area TEM micrograph of doped superlattice obtained from 10.2 $\pm 0.6 \mathrm{~nm} \mathrm{Au@2}$ and 9.5 $\pm 0.8 \mathrm{~nm}$ MZF@4. The FFT is shown as inset and the areas with 3 or more MZF NC clusters are marked. 

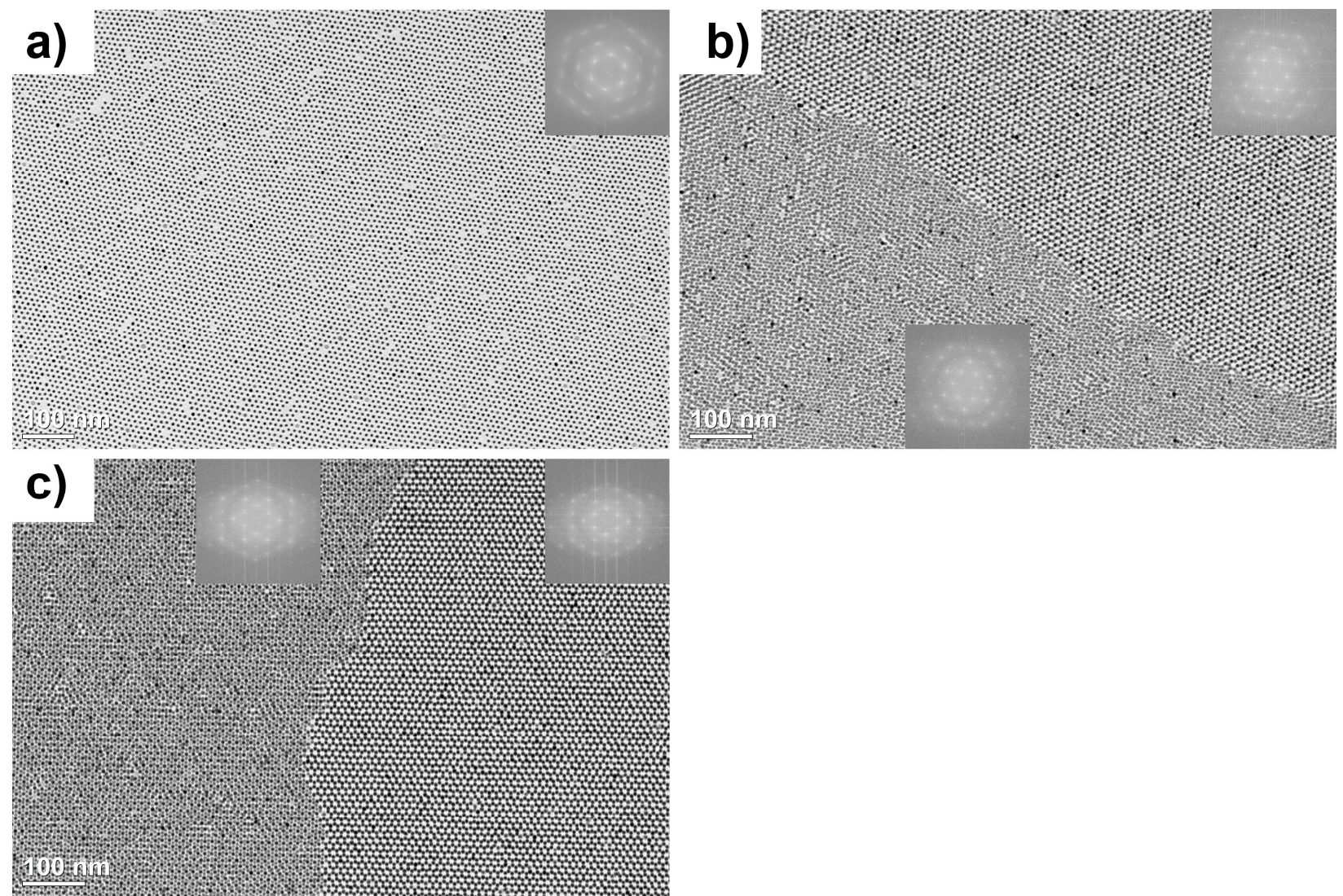

Figure S10. Large area TEM micrographs of single layer a) and multilayer of doped superlattices

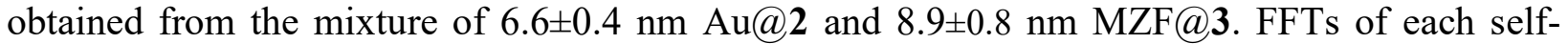
assembly pattern are also provided within corresponding patterns. 


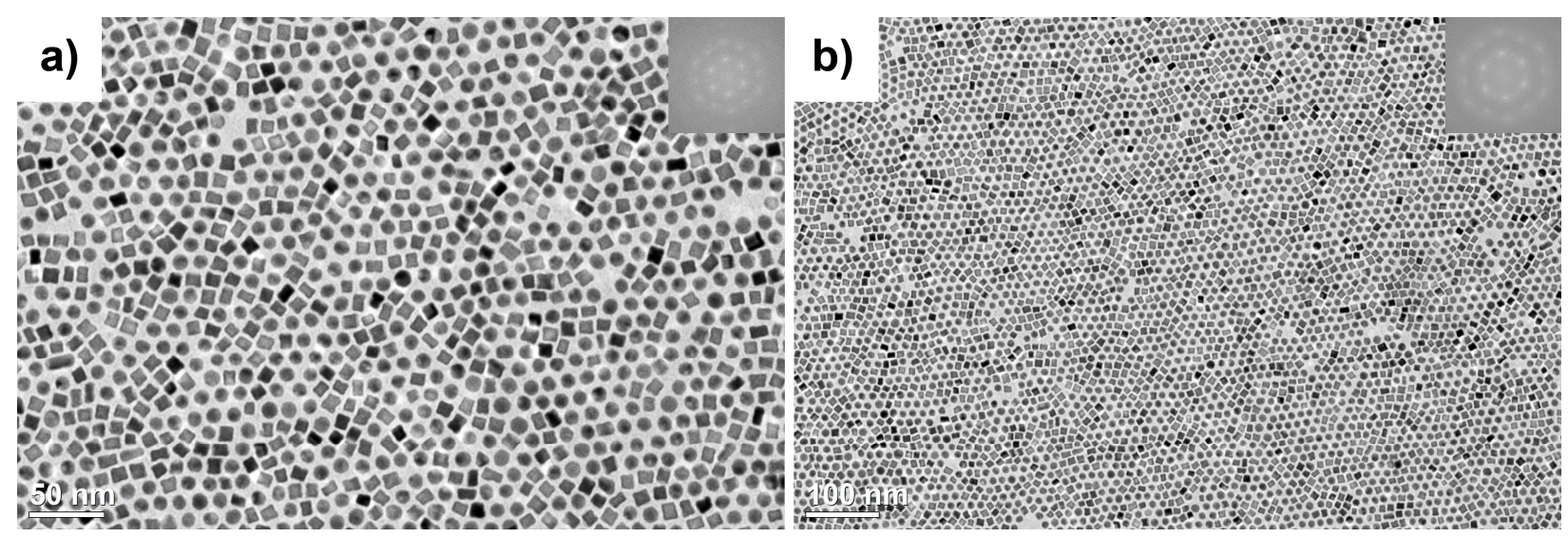

Figure S11. TEM micrographs of high (a) and low (b) resolution doped superlattices obtained from the mixture of 10.2 \pm 0.6 nmAu@2 and 9.5 \pm 0.8 nm Pt cubes@3. FFTs are provided as insets.

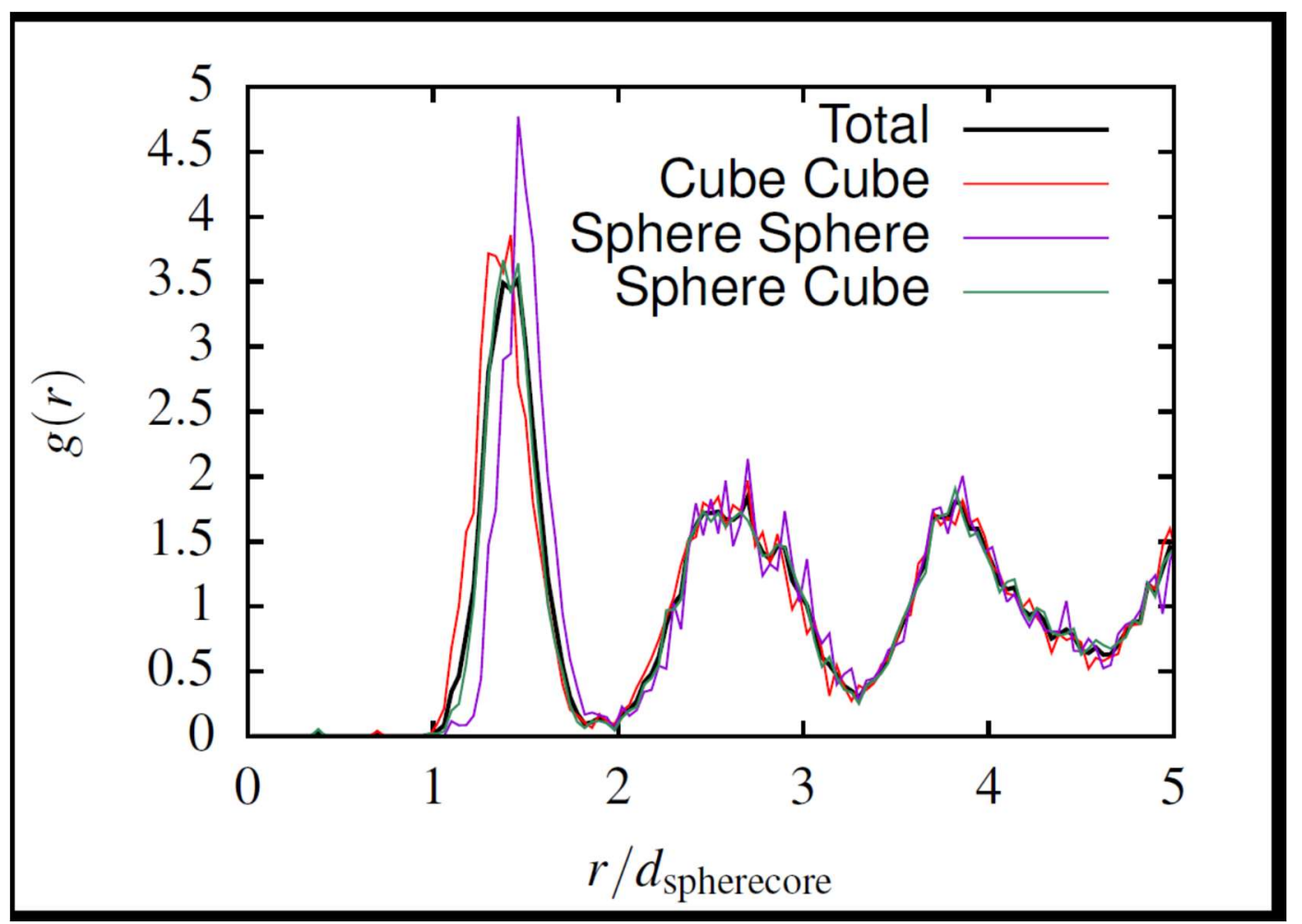

Figure S12. Particle tracking data for doped superlattice obtained from the mixture of $10.2 \pm 0.6$ nmAu@2 and 9.5 \pm 0.8 nm Pt cubes@3. 